\title{
Cognitive dysfunction, elevated anxiety, and reduced cocaine response in circadian clock-deficient cryptochrome knockout mice
}

\author{
Dimitri De Bundel ${ }^{1,2,3 * t}$, Giuseppe Gangarossa ${ }^{1,2,3+}$, Anne Biever ${ }^{1,2,3}$, Xavier Bonnefont $^{1,2,3}$ and \\ Emmanuel Valjent ${ }^{1,2,3 *}$
}

' CNRS, UMR-5203, Institut de Génomique Fonctionnelle, Montpellier, France

2 INSERM, U661, Montpellier, France

${ }^{3}$ Universités de Montpellier 1 and 2, UMR-5203, Montpellier, France

\section{Edited by:}

Angela Roberts, University of

Cambridge, UK

Reviewed by:

Emma Robinson, Bristol University, UK

Michael Hastings, University of Cambridge, UK

*Correspondence:

Dimitri De Bundel and Emmanuel Valjent, Inserm U661, CNRS UMR

5203, Institut de Génomique

Fonctionnelle, Universités

Montpellier 1 \& 2, 141 rue de la

Cardonille, 34094 Montpellier,

Cedex 05, France

e-mail: ddebundel@hotmail.com; emmanuel.valjent@gmail.com

these authors have contributed equally to this work.
The circadian clock comprises a set of genes involved in cell-autonomous transcriptional feedback loops that orchestrate the expression of a range of downstream genes, driving circadian patterns of behavior. Cognitive dysfunction, mood disorders, anxiety disorders, and substance abuse disorders have been associated with disruptions in circadian rhythm and circadian clock genes, but the causal relationship of these associations is still poorly understood. In the present study, we investigate the effect of genetic disruption of the circadian clock, through deletion of both paralogs of the core gene cryptochrome (Cry1 and Cry2). Mice lacking Cry1 and Cry2 $\left(\mathrm{Cry}^{-/-}{ }^{-C r y} 2^{-/-}\right.$) displayed attenuated dark phase and novelty-induced locomotor activity. Moreover, they showed impaired recognition memory but intact fear memory. Depression-related behaviors in the forced swim test or sucrose preference tests were unaffected but Cry $1^{-1-} \mathrm{Cry}^{-1-}$ mice displayed increased anxiety in the open field and elevated plus maze tests. Finally, hyperlocomotion and striatal phosphorylation of extracellular signal-regulated kinase (ERK) induced by a single cocaine administration are strongly reduced in $\mathrm{Cry}^{-1-} \mathrm{Cry}^{-/-}$mice. Interestingly, only some behavioral measures were affected in mice lacking either Cry1 or Cry2. Notably, recognition memory was impaired in both $\mathrm{Cry}^{-/-} \mathrm{Cry}^{+/+}$and $\mathrm{Cry} 1^{+/+} \mathrm{Cry}^{-/-}$mice. Moreover, we further observed elevated anxiety in $\mathrm{Cry}^{-1-} \mathrm{Cry} 2^{+/+}$and $\mathrm{Cry} 1^{+/+} \mathrm{Cry} 2^{-1-}$ mice. Our data indicate that beyond their role in the control of circadian rhythm, cryptochrome genes have a direct influence in cognitive function, anxiety-related behaviors and sensitivity to psychostimulant drugs.

\section{Keywords: Cry1 and Cry2 knockout mice, mood-related disorder, psychostimulants, learning}

\section{INTRODUCTION}

In mammals, light entrains the central circadian oscillator in the suprachiasmatic nucleus of the hypothalamus (SNC), which in turn synchronizes subsidiary oscillators throughout the brain and other organs. This hierarchical system controls circadian activity and orchestrates the expression of a range of downstream genes that allow the organism to anticipate daily changes in the environment (Mohawk et al., 2012). These events are tightly regulated by the molecular clockwork, which is composed of a series of genes involved in transcriptional feedback loops with a circadian oscillation of activity (Mohawk et al., 2012). The translation products of the circadian clock genes Circadian locomotor output cycles kaput (CLOCK) and PAS-domain protein 2 (NPAS2) form heterodimers with brain and muscle ARNTL-like proteins (BMAL1, BMAL2) to activate the transcription of other genes, including periods (mPer1, mPer2, mPer 3 ) and cryptochromes (Cry1, Cry2). Their translation products, PER and CRY, in turn heterodimerize and repress the transcriptional activity of the complex formed by CLOCK/NPAS2-BMAL1/2 (Takahashi et al., 2008). As such, clock genes control circadian activity allowing the organism to anticipate daily changes in the environment (Takahashi et al., 2008; Mohawk et al., 2012).

Beyond their role in the control of circadian rhythm by light, several studies have pointed out that circadian clock genes may have a more widespread influence on cognition, mood, anxiety, and reward-related behaviors (Wulff et al., 2010). Single nucleotide polymorphisms in core circadian clock genes have been associated with autism spectrum disorders (Nicholas et al., 2007); attention deficit hyperactivity disorder (Kissling et al., 2008; Xu et al., 2010), major depressive disorder (Partonen et al., 2007; Lavebratt et al., 2010; Soria et al., 2010), bipolar disorder (Nievergelt et al., 2006; Shi et al., 2008; Soria et al., 2010), anxiety disorders (Sipila et al., 2010) and substance abuse disorders (Kovanen et al., 2010; Dong et al., 2011; Wang et al., 2012). However, the causal relationship for these associations remains poorly understood. Circadian clock genes may affect specific aspects of psychiatric disorders through circadian control or through distinct regulation of downstream effectors. Indeed, an emerging body of evidence suggests opposing actions on behavioral output by circadian transcriptional 
activators (CLOCK, NPAS2, BMAL1, BMAL2) and transcriptional repressors (PER1, PER2, CRY1, CRY2). Moreover, circadian clock genes exist in paralog pairs with often complementary but not necessarily identical functions (Vitaterna et al., 1999; Zheng et al., 2001; De Bundel et al., 2013; Shi et al., 2010). These functional differences may reflect region-dependent clock gene expression and paralog-specific control over output genes (Hampp and Albrecht, 2008).

In the present study, we perform an in depth characterization of behaviors relevant to psychiatric disease in $\mathrm{Cry} 1^{-/-} / \mathrm{Cr} y 2^{+/+}$, $\mathrm{Cry} 1^{+/+} / \mathrm{Cr} y 2^{-/-}$, and $\mathrm{Cry} 1^{-/-} / \mathrm{Cry} 2^{-/-}$mice. In doing so, we aim to address the causality between circadian gene disruption and psychiatric disease. These novel findings reveal previously unappreciated and complementary roles for Cry1 and Cry2 in regulating cognitive function, anxiety-like behavior and sensitivity to psychostimulants and support the hypothesis that circadian activator and repressor genes exert opposite control over a range of behavioral outputs.

\section{MATERIALS AND METHODS ANIMALS AND ETHICS}

Double heterozygous $C r y 1^{+/-} / C r y 2^{+/-}$mice were obtained by breeding $\mathrm{Cry} \mathrm{1}^{+/-}$and $\mathrm{Cry} 2^{+/-}$mice (van der Horst et al., 1999), previously backcrossed for at least 12 generations with the C57/Bl6 strain (Charles River, L'Arbresle, France). They were then intercrossed to generate $\mathrm{Cr} y 1^{-/-} / \mathrm{Cr} y 2^{+/+}, \mathrm{Cr} y 1^{+/+} / \mathrm{Cr} y 2^{-/-}$, Cry $1^{-/-} / C r y 2^{-/-}$mice and their control wild type (WT) littermates. Initial experiments were carried out on a cohort of WT and Cry $1^{-/-} / \mathrm{Cr} y 2^{-/-}$mice. Further comparisons between all genotypes were performed on a separate cohort of animals and are represented in the table and separate graphs. All animals were housed in a $12 \mathrm{~h}$-light $/ 12 \mathrm{~h}$-dark light cycle with food and water provided ad libitum. Animals were housed under standard laboratory conditions with free access to food and water in a $12 \mathrm{~h}$ light-dark cycle with lights on at 7:00 (ZT 0). All behavioral experiments were carried out during the light phase between ZT 4-10 with male mice, since baseline activity showed minimal differences between genotypes at this time of the light-dark cycle. Mice were age-matched, between 8 and 12 weeks. Spontaneous locomotor activity, open field activity, objects recognition memory and anxiety in the elevated plus maze were determined on the same animals in this order in a series of behavioral tests. Next, one of the following behaviors was evaluated for a given batch of mice: sucrose preference, fear conditioning, or cocaine sensitization. All experiments were in accordance with the guidelines of the French Agriculture and Forestry Ministry for handling animals (authorization number/license D34-172-13).

\section{NOVELTY-INDUCED AND CIRCADIAN LOCOMOTOR ACTIVITY}

Horizontal and vertical activity was measured in a circular corridor (Imetronic, Pessac, France). Counts for horizontal activity were incremented by consecutive interruption of two adjacent beams placed at a height of $1 \mathrm{~cm}$ per $90^{\circ}$ sector of the corridor (mice moving through one-quarter of the circular corridor) and counts for vertical activity (rearings) corresponding to interruption of beams placed at a height of $7.5 \mathrm{~cm}$ along the corridor (mice stretching upwards) were used as an additional measure for exploratory activity. Data were pooled for all experiments during which mice were habituated to the circular corridor. For circadian locomotor activity, a $12 \mathrm{~h}$ dark/light cycle was maintained. Naïve animals were introduced into the apparatus at ZT 5 and had free access to food and water for the duration of the experiment. ZT5 was selected as the start time of the experiment to enable habituation to the apparatus prior to the onset of the dark phase, as described previously (McClung et al., 2005).

\section{OBJECT RECOGNITION}

Mice were habituated to an open field (white plastic box with $35 \mathrm{~cm}$ width $\times 45 \mathrm{~cm}$ length $\times 25 \mathrm{~cm}$ height) for $10 \mathrm{~min}$ on 2 consecutive days. The following day, mice were allowed to freely explore 2 objects (A and B) placed $10 \mathrm{~cm}$ from opposite walls of the open field until the criterion of $40 \mathrm{~s}$ total object interaction was reached. Object interaction was defined as approaching the object with the nose closer than $1 \mathrm{~cm}$. Following a retention interval of $24 \mathrm{~h}$, mice underwent a $5 \mathrm{~min}$ recall session during which the open field contained a familiar object (A) and a novel object (C). Replicate objects were used to avoid smell traces. Following each session, the objects and the open field were cleaned with 70\% ethanol. The experiments were filmed and an observer blinded to genotype performed scoring. A retention index was calculated using the formula $\mathrm{RI}=(\mathrm{C}-\mathrm{A}) /(\mathrm{A}+\mathrm{C})$.

\section{FEAR CONDITIONING}

Pavlovian fear conditioning was performed in a conditioning box $(20 \mathrm{~cm}$ width $\times 20 \mathrm{~cm}$ length $\times 20 \mathrm{~cm}$ height $)$ placed within a sound proof chamber (Panlab, Harvard Apparatus). Two different contexts were used for training and testing (A: white walls, metal grid on black floor, washed with $1 \%$ acetic acid; B: black walls, white rubber floor, washed with $70 \%$ ethanol). Mice were conditioned in context A. After 2 min habituation, mice received three pairings (60-120 s variable pairing interval) of a conditioned stimulus (CS: $7.5 \mathrm{kHz}, 80 \mathrm{~dB}, 30 \mathrm{~s}$ tone) with an unconditioned stimulus (US: 2 s, $0.6 \mathrm{~mA}$ scrambled footshock) using a Freezing system (Panlab, Barcelona, Spain). Following a $24 \mathrm{~h}$ retention interval, mice were habituated for $2 \mathrm{~min}$ in context $\mathrm{B}$ and tested for fear memory by 4 presentations of CS (with 60-120 s variable interval). Freezing was measured using a load cell coupler (Panlab, Barcelona, Spain) and was defined as the lack of activity above a body weight-corrected threshold for a duration of $1 \mathrm{~s}$ or more as analyzed using Freezing software (Panlab, Barcelona, Spain).

\section{FORCED SWIM TEST}

Mice were assessed for spontaneous depression-related behavior using a modified version of the forced swim test (Porsolt et al., 1977). Behavioral despair was evaluated in a single $10 \mathrm{~min}$ forced swim session. Mice were placed for $10 \mathrm{~min}$ in a glass beaker $(15 \mathrm{~cm}$ width $\times 20 \mathrm{~cm}$ height) half filled water at $25^{\circ} \mathrm{C}$ so that they were unable to touch the bottom of the beaker with their hind paws. The beakers were filled with fresh water between sessions. Passive immobility was scored per 2 min intervals by an observer blinded to genotype. Immobility was defined as the lack of movements except those required for keeping the head above the water (essentially no movement in three or four paws). 


\section{SUCROSE PREFERENCE}

Sucrose preference was evaluated using a two-bottle free choice paradigm. Mice were housed individually with access to 2 identical drinking bottles containing $1 \%$ sucrose in water or water. On 3 consecutive days, liquid consumption in each bottle was measured at the onset of every dark and light phase, while switching the location of the drinking bottles every $12 \mathrm{~h}$ to avoid side bias.

\section{OPEN FIELD}

Spontaneous exploratory behavior was monitored in an open field (white plastic box with $35 \mathrm{~cm}$ width $\times 45 \mathrm{~cm}$ length $\times 25 \mathrm{~cm}$ height) for $10 \mathrm{~min}$. The open field was wiped with $70 \%$ ethanol between sessions. The center zone was defined as a virtual perimeter within $5 \mathrm{~cm}$ from the sides of the box. Experiments were filmed and an observer blinded to genotype scored the time spent in the center (4 paws inside the center zone) and the number of midline crosses ( 4 paws crossing a midline of the box).

\section{ELEVATED PLUS MAZE}

The elevated plus maze was elevated $1 \mathrm{~m}$ above the floor and was constructed of black plastic with 2 open arms $(5 \mathrm{~cm}$ width $\times 35 \mathrm{~cm}$ length $\times 0.5 \mathrm{~cm}$ height of the walls) and 2 closed arms ( 5 width $\times 35 \mathrm{~cm}$ length $\times 15 \mathrm{~cm}$ height of the walls). Mice were placed in the center of an elevated plus maze facing one of the closed arms and were allowed to explore the maze for $5 \mathrm{~min}$. The elevated plus maze was wiped with $70 \%$ ethanol between sessions. Experiments were filmed and an observer blinded to genotype performed scoring for entries and time spent in the closed arms (4 paws within closed arm) or open arms (4 paws within open arms).

\section{ROTAROD}

Motor learning was assessed using a mouse accelerating rotarod (Ugo Basile). Mice were placed on the rotating drum that accelerated from 4 to $40 \mathrm{rpm}$ over $5 \mathrm{~min}$ for three trials a day, for 3 consecutive days. The intertrial interval was $45 \mathrm{~min}$ for all the mice. Rotarod scores were scored for latency to either fall or ride the rod around.

\section{COCAINE-INDUCED LOCOMOTOR ACTIVITY AND SENSITIZATION}

Cocaine hydrocloride (Sigma) was dissolved in 0.9\% physiological saline and injected intraperitoneally (i.p.) in a body volume of $10 \mathrm{ml} / \mathrm{kg}$. Locomotor activity was measured in the same apparatus as used for novelty-induced and circadian locomotor activity, as described previously (Brami-Cherrier et al., 2005). All mice were habituated to the test apparatus, handling, and procedure for three consecutive days before the actual experiment. In this habituation procedure mice were placed for $30 \mathrm{~min}$ in the activity box, received a first injection of saline, and were placed back in the box for $1 \mathrm{~h}$. For the acute drug injection (day 4), the handling was identical, except that the saline injection was replaced by cocaine injection (7.5 and $15 \mathrm{mg} / \mathrm{kg}$, i.p.) as described previously (Bertran-Gonzalez et al., 2008). In cocaine sensitization experiments, mice were treated repeatedly with cocaine (7.5 and $15 \mathrm{mg} / \mathrm{kg}$, i.p., every day) for 5 consecutive days. This repeated exposure was followed by 12 days of withdrawal and by a challenge injection of cocaine $(7.5$ and $15 \mathrm{mg} / \mathrm{kg})$. Locomotor activity was measured as described above on day 4 .

\section{IMMUNOBLOTTING}

Mice were sacrificed for preparation of the samples for western blotting between ZT 4-6. After immersion in liquid nitrogen for $4 \mathrm{~s}$, the brains were removed and the striata were quickly dissected out on ice-cold surface, sonicated in $350 \mu \mathrm{l}$ of $10 \%$ SDS and boiled for $10 \mathrm{~min}$. Aliquots $(2.5 \mu \mathrm{l})$ of the homogenate were used for protein determination using a BCA assay kit (Pierce Europe). Equal amounts of proteins $(15 \mu \mathrm{g})$ for each sample were loaded onto $8-10 \%$ polyacrylamide gels. Proteins were separated by SDSPAGE and transferred to PVDF membranes (GE Healthcare). The membranes were immunoblotted using anti-diphospho ERK1/2 (1:2000; Cell Signaling Technology), ERK1/2 (1:2000; Cell Signaling Technology) and $\beta$-actin (1:40000; Abcam) antibodies. Bound antibodies were detected with HRP-conjugated anti-rabbit or anti-mouse antibodies (1:10000; Cell Signaling Technology) and visualized by enhanced chemiluminescence detection. Quantifications were performed using ImageJ.

\section{TISSUE PREPARATION AND IMMUNOFLUORESCENCE}

As previously described (Bertran-Gonzalez et al., 2008), mice were rapidly anaesthetized by i.p. injection of pentobarbital (500 mg/kg, i.p., Sanofi-Aventis, France) prior to intracardiac perfusion of $4 \%$ (weight/vol) paraformaldehyde (PFA) in $0.1 \mathrm{M}$ $\mathrm{Na}_{2} \mathrm{HPO}_{4} / \mathrm{NaH}_{2} \mathrm{PO}_{4}$ buffer, $\mathrm{pH} 7.5$, delivered with a peristaltic pump at $20 \mathrm{ml} / \mathrm{min}$ during $5 \mathrm{~min}$. Perfusions were performed between ZT 4-10. Thirty- $\mu \mathrm{m}$ thick sections were cut with a vibratome (Leica, France) and processed as follows: free-floating sections were rinsed in Tris-buffered saline (TBS: $0.25 \mathrm{M}$ Tris

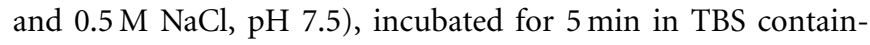
ing $3 \% \mathrm{H}_{2} \mathrm{O}_{2}$ and $10 \%$ methanol and rinsed in TBS. After $15 \mathrm{~min}$ incubation in $0.2 \%$ Triton $\mathrm{X}-100$ in TBS, sections were rinsed in TBS and incubated overnight at $4^{\circ} \mathrm{C}$ with the primary antibody: rabbit anti-diphospho signal-regulated kinase (ERK) (phosphoThr202-Tyr204-ERK1/2, cat-9101; Cell Signaling Technology, Beverly, MA, USA, dilution 1:400) overnight at $4^{\circ} \mathrm{C}$. After three rinses in TBS, sections were incubated for $45 \mathrm{~min}$ at room temperature with the secondary fluorescent goat antibodies (1:400 Cy3 coupled anti-rabbit IgG, Jackson ImmunoReasearch Europe Ltd) in TBS. Sections were then rinsed twice in TBS and twice in $\mathrm{TB}$ and mounted on a slide under coverslips using 1,4-diazabicyclo-[2. 2. 2]-octane (DABCO, Sigma-Aldrich). Confocal microscopy and image analysis were carried out at the Montpellier RIO Imaging Facility. Single-labeled images $(636.4 \times$ $636.4 \mu \mathrm{m}$ ) from each region of interest were obtained bilaterally using laser scanning confocal microscopy (Zeiss LSM510 META). Photomicrographs were obtained with the following band-pass setting: Cy3 (band pass filter: 560-615). P-ERK immunoreactive labeled neurons were pseudocolored red. The analysis was performed by counting nuclear or cytosolic Cy3 immunofluorescence. Quantification of immunoreactive cells was performed using Image-J and taking as standard reference a fixed threshold of fluorescence.

\section{STATISTICAL ANALYSIS}

Results are presented as mean \pm sem. Within group comparisons to chance levels were performed using paired two-tailed $t$-test and differences between groups were analyzed using the 
unpaired two-tailed $t$-tests or One- or Two-Way analysis of variance (ANOVA) followed by Bonferroni's post-hoc test for comparison of multiple groups where applicable. Differences were considered significant for $p<0.05$. Statistical analyses were performed using GraphPad Prism 5.0 (GraphPad Prism Software Inc., San Diego, USA).

\section{RESULTS}

\section{LOW SPONTANEOUS AND CIRCADIAN LOCOMOTOR ACTIVITY IN Cry1-/-Cry2-/- MICE}

Cry $1^{-/-}$Cry $2^{-/-}$mice are fully arrhythmic in constant darkness but maintain a daily pattern of activity when kept in a $12 \mathrm{~h}$ light-dark cycle (van der Horst et al., 1999). We investigated locomotor activity of $\mathrm{Cr} y 1^{-/-} \mathrm{Cr} y 2^{-/-}$mice in response to novelty, in a non-stressful environment (low luminosity), and over a $24 \mathrm{~h}$ period in a $12 \mathrm{~h}$ light/dark cycle. When placed in a novel environment, $\mathrm{Cry} 1^{-/-} \mathrm{Cry} 2^{-/-}$mice show an initial period of high horizontal locomotion (ambulations) that declined more rapidly compared to WT mice (Figure 1A, top panel). Moreover, Cry $1^{-/-}$Cry $2^{-/-}$mice showed low vertical locomotion (rearings) compared to WT mice throughout the initial habituation period (Figure 1A, bottom panel). Over a $24 \mathrm{~h}$ period, WT mice showed a clear daily pattern of activity, with peaks of horizontal locomotion (ambulations) at the onset and at the end of the dark phase. Cry $1^{-/-}$Cry $2^{-/-}$mice also had a daily pattern of horizontal activity that increased at the onset of the dark phase but remained low compared to WT mice (Figure 1B, top panel). Similarly, a daily pattern of vertical locomotor activity (rearings) could be observed that peaked at the onset of the dark phase but remained low at the end of the dark phase in $\mathrm{Cr} y 1^{-/-} \mathrm{Cr} y 2^{-/-}$mice compared to WT mice (Figure 1B, bottom panel). Interestingly, the hypoactive phenotype was specific for mice lacking both Cryl and Cry2. Cry $1^{-/-} \mathrm{Cr} y 2^{+/+}$and $\mathrm{Cr} y 1^{+/+} \mathrm{Cr} y 2^{-/-}$single knockout mice showed a normal habituation to a novel environment, and a preserved overall dark phase locomotor activity (Table 1).

\section{COGNITIVE DYSFUNCTION IN Cry1-/- Cry2-/- MICE}

Cognitive dysfunction is an endophenotype and co-morbid risk factor for mood, anxiety, and substance abuse disorders (Disner et al., 2011; Millan et al., 2012). We investigated memory formation in cryptochrome mutant mice using the object recognition task. Compared to WT mice, Cry $1^{-/-}$Cry $2^{-/-}$mice showed low exploratory drive and required significantly more time to reach the criterion of $40 \mathrm{~s}$ total object exploration during the training session (Figure 2A). Cry $1^{-/-} \mathrm{Cr} y 2^{-/-}$mice that reached this criterion did not show a preference for the novel object during the test session $24 \mathrm{~h}$ later as opposed to WT mice (Figure 2A). Interestingly, Cry $1^{-/-} \mathrm{Cr} y 2^{+/+}$mice and $\mathrm{Cry1} 1^{+/+} \mathrm{Cry2}^{-/-}$mice showed normal object exploration, but were similarly unable to recognize the novel object during the test session $24 \mathrm{~h}$ later (Table 1). To ascertain whether the observed learning deficit in $C r y 1^{-/-} C r y 2^{-/-}$mice was specific to recognition memory, we further investigated their learning capacity in an auditory fear-conditioning task. Cry $1^{-/-} \mathrm{Cr} y 2^{-/-}$ mice rapidly learned the tone-shock association and displayed significantly higher freezing levels during auditory fear
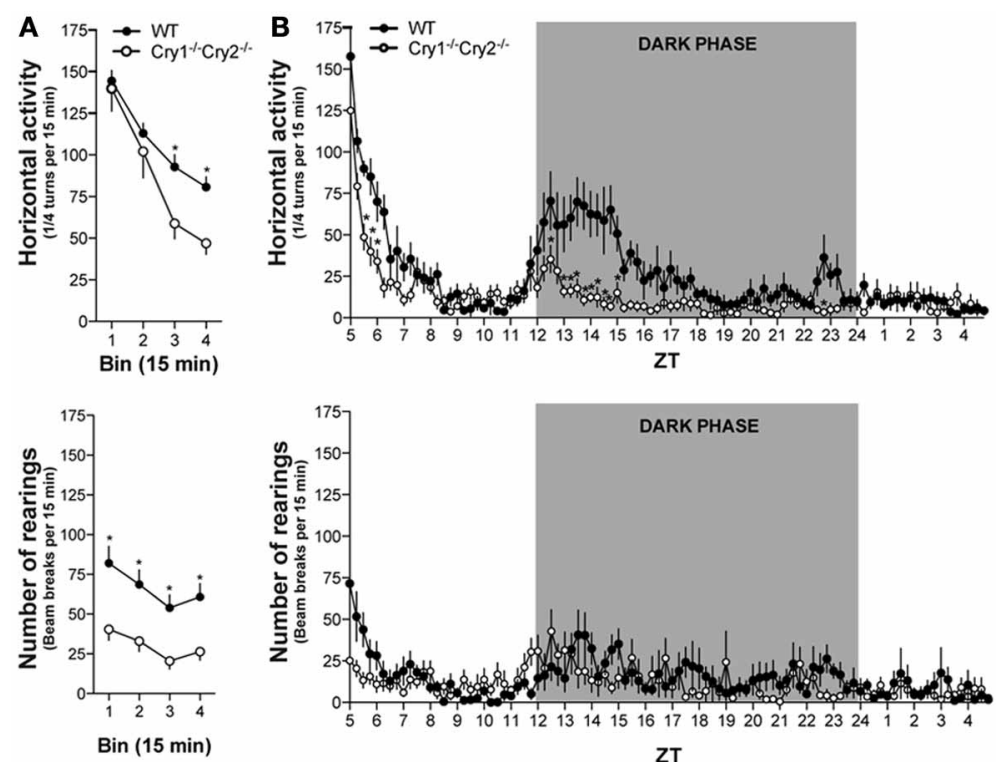

FIGURE 1 | Spontaneous locomotor activity in Cry1-/-Cry2-/- mice. (A) When exposed to an enclosed environment, horizontal activity (top panel) declined more rapidly [Genotype $\times$ Time: $F_{(3,111)}=3.29, P=0.023$; Genotype: $F_{(1,37)}=3.70, P=0.062$; Time: $\left.F_{(3,111)}=69.21, P<0.0001\right]$ and vertical activity (bottom panel) remained low [Genotype $\times$ Time:

$F_{(3,111)}=0.27, P=0.84$; Genotype: $F_{(1,37)}=14.43, P=0.0005$; Time:

$\left.F_{(3,111)}=8.66, P<0.0001\right]$ during the initial habituation period in

Cry $1^{-/}$Cry2 ${ }^{-/}-$mice $(n=18)$ compared to wild type (WT) mice $(n=21)$.
(B) Over a circadian period, the increase in horizontal activity during the dark phase (top panel) was lower [Genotype $\times$ Time: $F_{(95,1520)}=3.48, P<0.0001$; Genotype: $F_{(1,16)}=49.60, P=0.015$; Time: $\left.F_{(95,1520)}=18.54, P<0.0001\right]$ in $\mathrm{Cry}^{-/-} \mathrm{Cry}^{-/-}$mice compared to WT mice. Similarly, the increase in vertical activity during the dark phase (bottom panel) was less pronounced [Genotype $\times$ Time: $F_{(95,1520)}=1.59, P=0.0003$; Genotype: $F_{(1,16)}=1.79, P=0.20$; Time: $\left.F_{(95,1520)}=4.89, P<0.0001\right]$ in $\mathrm{Cry}^{-1-} \mathrm{Cry}^{-1-}$ mice $(n=10)$ compared to WT mice $(n=8) .{ }^{*} P<0.05 \mathrm{Cry}^{-1-}{ }^{-1}$ ry $2^{-1-}$ mice vs. WT mice. 
Table 1 | Behavioral profile of cryptochrome mutant mice.

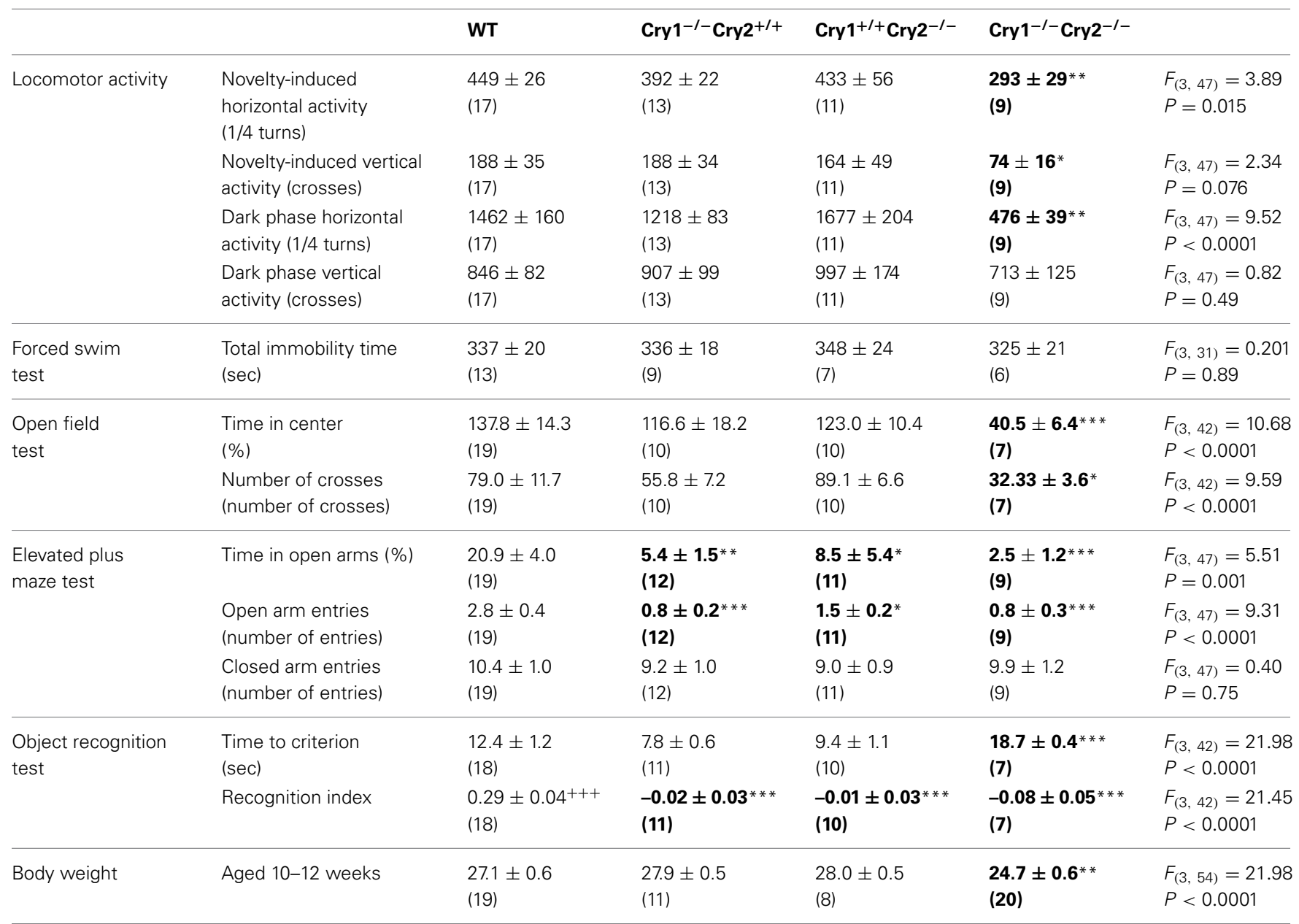

${ }^{*} p<0.05,{ }^{* *} p<0.01,{ }^{* *} p<0.001$ vs. WT, One-Way ANOVA and Bonferroni's post-hoc test.

${ }^{+++} p<0.001$ vs chance level one sample t-test.

The number of mice is specified between parentheses.

conditioning relative to WT mice. When tested $24 \mathrm{~h}$ later, Cry $1^{-/-}$Cry $2^{-/-}$mice displayed a clear freezing response to the conditioned tone, which did not differ from WT mice (Figure 2B). Taken together, these data suggest a specific role for both Cry1 and Cry2 genes in non-aversive episodic-like memory formation.

\section{LACK OF SPONTANEOUS DEPRESSION-LIKE BEHAVIOR IN Cry1-/-Cry2-/- MICE}

Several circadian clock genes have been associated with mood disorders in humans (Soria et al., 2010). This lead us to hypothesize that low exploratory drive in $\mathrm{Cr} y 1^{-/-} \mathrm{Cr} y 2^{-/-}$mice may be associated with a depression-like phenotype. We investigated the effect of Cry gene ablation on depression-like behavior, using a modified version of the forced swim test, with a single swim session to negate potentially confounding memory effects (De Bundel et al., 2013; Gomez-Galan et al., 2013). Surprisingly, we observed that immobility times did not differ between Cry $1^{-/-} \mathrm{Cry} 2^{-/-}$and WT mice (Figure 2C). Similarly, immobility times of both $\mathrm{Cry} 1^{-/-} \mathrm{Cr} y 2^{+/+}$and $\mathrm{Cry} 1^{+/+} \mathrm{Cr} y 2^{-/-}$ single knockout mice were not different from those in WT mice (Table 1). In addition, we investigated whether Cry $1^{-/-} C r y 2^{-/-}$ showed an altered preference for natural reward. We found no difference in the intake of a $1 \%$ sucrose solution between Cry $1^{-/-}$Cry $2^{-/-}$and WT mice (Figure 2D). Our data indicate that cryptochrome gene deletion does not cause depression-like behavior in mice.

\section{INCREASED ANXIETY-RELATED BEHAVIOR IN Cry1-/- Cry2-/- MICE}

Circadian clock genes have also been associated with anxiety disorders in humans (Sipila et al., 2010). Given that low exploratory activity and rearing in a novel environment may result from anxiety, we next investigated anxiety-related behaviors in $C r y 1^{-/-} C r y 2^{-/-}$mice. Compared to WT mice, $\mathrm{Cry1}^{-/-} \mathrm{Cr} y 2^{-/-}$mice were less active and spent significantly less time exploring the center zone in an open field (Figure 2E). Moreover, Cry $1^{-/-} \mathrm{Cr} y 2^{-/-}$mice made fewer entries and spent significantly less time in the open arms of an elevated plus maze compared to WT mice (Figure 2F). Cry $1^{-/-}$Cry $2^{-/-}$ mice made an equal number of closed arm entries indicating 


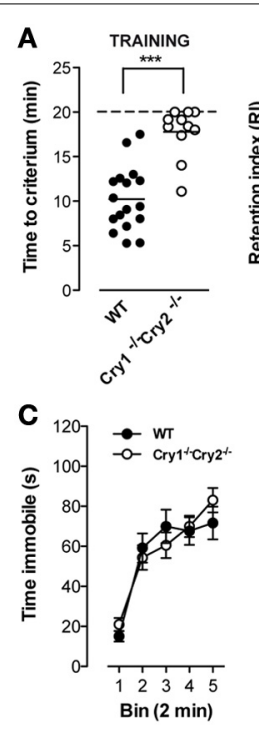

E
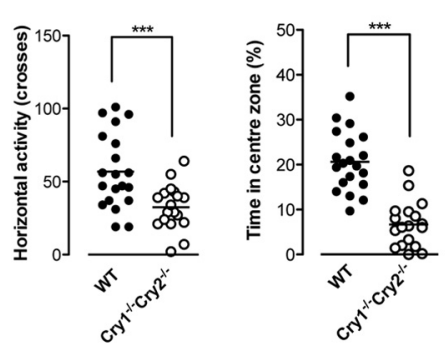

FIGURE 2 | Cognitive processing, depression-related behavior, and anxiety-related behavior in $\mathrm{Cry1}^{-/-} \mathrm{Cry}^{-/-}$mice. (A) During the training phase of the object recognition test (left panel), Cry1 ${ }^{-/-} \mathrm{Cry} 2^{-/-}$ mice $(n=11)$ required more time $\left[t_{(26)}=5.971, P<0.0001\right]$ to reach the criterion of $40 \mathrm{~s}$ total object exploration compared to wild type (WT) mice ( $n=17$ ). During the test phase, $24 \mathrm{~h}$ later, Cry ${ }^{-/}-\mathrm{Cry}^{-/-}$mice did not show a preference for the novel object as opposed $\left[t_{(26)}=3.895\right.$, $P=0.0006$ ] to WT mice, which had a retention index above 0 $\left[t_{(16)}=7.389, P<0.0001\right]$. (B) In the auditory fear conditioning test, Cry $1^{-/-} \mathrm{Cry}^{-/-}$mice $(n=8)$ readily associate the tone with the ensuing foot shock, but display higher [Genotype $\times$ Time: $F_{(3,45)}=2.52$, $P=0.07$; Genotype: $F_{(1,45)}=10.81, P=0.005$; Time: $F_{(3,45)}=58.98$, $P<0.0001]$ freezing levels compared to WT mice $(n=10)$. During the test, $24 \mathrm{~h}$ later, both genotypes showed an elevated freezing response to tone presentation [Genotype $\times$ Time: $F_{(17,204)}=0.58, P=0.9$;

Genotype: $F_{(1,204)}=0.03, P=0.86$; Time: $F_{(17,204)}=30.32$,

$P<0.0001]$. (C) In the forced swim test, immobility times did not differ [Genotype $\times$ Time: $F_{(4,96)}=1.52, P=0.20$; Genotype: $F_{(1,96)}=0.03$, $P=0.87$; Time: $\left.F_{(4,96)}=47.61, P<0.0001\right]$ between $\mathrm{Cry1}^{-1-} \mathrm{Cry}^{-1-}$ mice $(n=8)$ and WT mice $(n=13)$. (D) In the sucrose preference test,
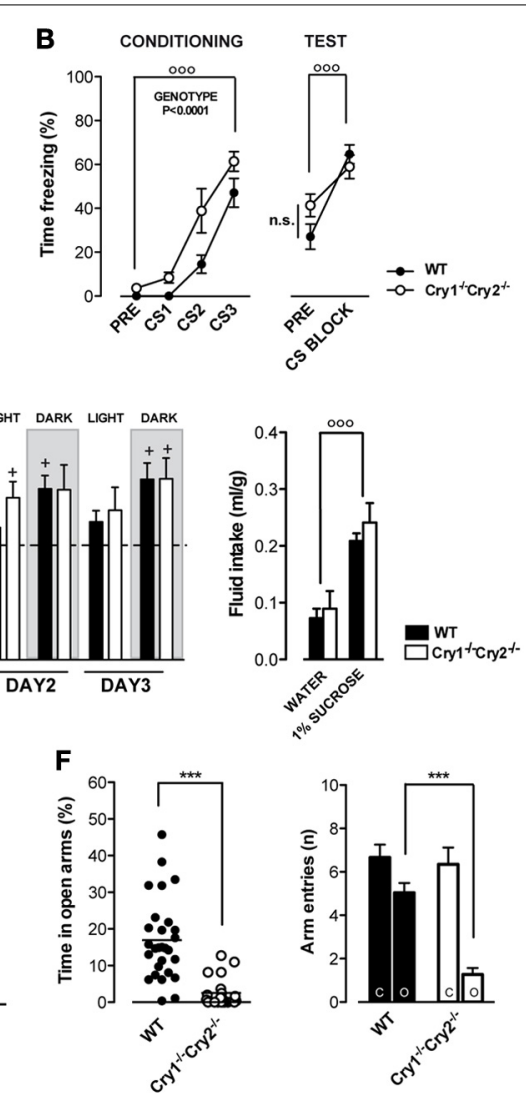

both $\mathrm{Cry}^{-1-} \mathrm{Cry}^{-/-}$mice $(n=8)$ and WT mice $(n=12)$ expressed a clear preference (left panel) for $1 \%$ sucrose over water [Genotype $\times$ Treatment: $F_{(5,90)}=1.05, P=0.39$; Genotype: $F_{(1,90)}=0.12, P=0.73$; Treatment: $F_{(5,90)}=5.91, P<0.0001$ ] and total fluid intake (right panel) was significantly higher for $1 \%$ sucrose over water in both genotypes [Genotype $\times$ Treatment: $F_{(5,90)}=1.05, P=0.39$; Genotype:

$F_{(1,90)}=0.12, P=0.73$; Treatment: $\left.F_{(2,26)}=10.75, P<0.0004\right]$. (E) In the open field test, overall activity (left panel) was lower $\left[t_{(36)}=3.498\right.$, $P=0.0013]$ in $\mathrm{Cry}^{-/-} \mathrm{Cry}^{-/-}$mice compared to WT mice. Moreover, the time spent in the center of the open field (right panel) was lower $\left[t_{(36)}=7.225, P<0.0001\right]$ in $C r y 1^{-/-}$Cry2 $2^{-1-}$ mice $(n=18)$ compared to WT mice $(n=20)$. (F) In the elevated plus maze test, Cry ${ }^{-1-C r y 2^{-1-}}$ mice $(n=18)$ spent less $\left[t_{(47)}=5.75, P<0.0001\right]$ time in the open arms compared to WT mice $(n=20)$. Moreover, the number of arm entries was lower for the open arms but not for the closed arms of the plus maze in $\mathrm{Cry}^{-1-} \mathrm{Cry}^{-1-}$ mice compared to WT mice [Genotype $\times$ Arm: $F_{(1,51)}=11.80, P=0.0012$; Genotype: $F_{(1,51)}=11.43, P=0.0014$; Arm: $F_{(17,204)}=44.67, P<0.0001$ ]. ( $^{* *} P<0.001 \mathrm{Cry1}^{-/}-\mathrm{Cry} 2^{-/}$mice vs. WT mice. ${ }^{+} P<0.05$ vs. chance level. ${ }^{+++} P<0.001$ vs. chance level. ${ }^{\circ 0 \circ} P<0.001$ for treatment or time effect. increased anxiety in the exposed center of the open field and open arms of the elevated plus maze rather than a general locomotor deficit. Altogether, these data confirmed low exploratory drive in $C r y 1^{-/-} C r y 2^{-/-}$mice and revealed that these mutant mice displayed an increased anxiety. Interestingly, open field exploratory activity was not significantly different from WT mice in $\mathrm{Cry1}^{-/-} \mathrm{Cry} 2^{+/+}$and $\mathrm{Cry} 1^{+/+} \mathrm{Cry} 2^{-/-}$mice (Table 1). However, the number of open arm entries and time spent in the open arms of the elevated plus maze were significantly lower compared to WT mice in $C r y 1^{-/-} \mathrm{Cr} y 2^{+/+}$and in
Cry $1^{+/+}$Cry $2^{-/-}$mice (Table 1) suggesting that cryptochromes influence anxiety-related behaviors.

\section{COCAINE-INDUCED ACUTE HYPERLOCOMOTION AND LOCOMOTOR SENSITIZATION IN Cry1-/- Cry2-/- MICE}

Recent studies highlight a link between disrupted circadian rhythms and cocaine sensitivity (Falcon and McClung, 2009). Single administration of cocaine induces acute locomotor hyperactivity and repeated administrations induce locomotor sensitization or incremental locomotor hyperactivity in 


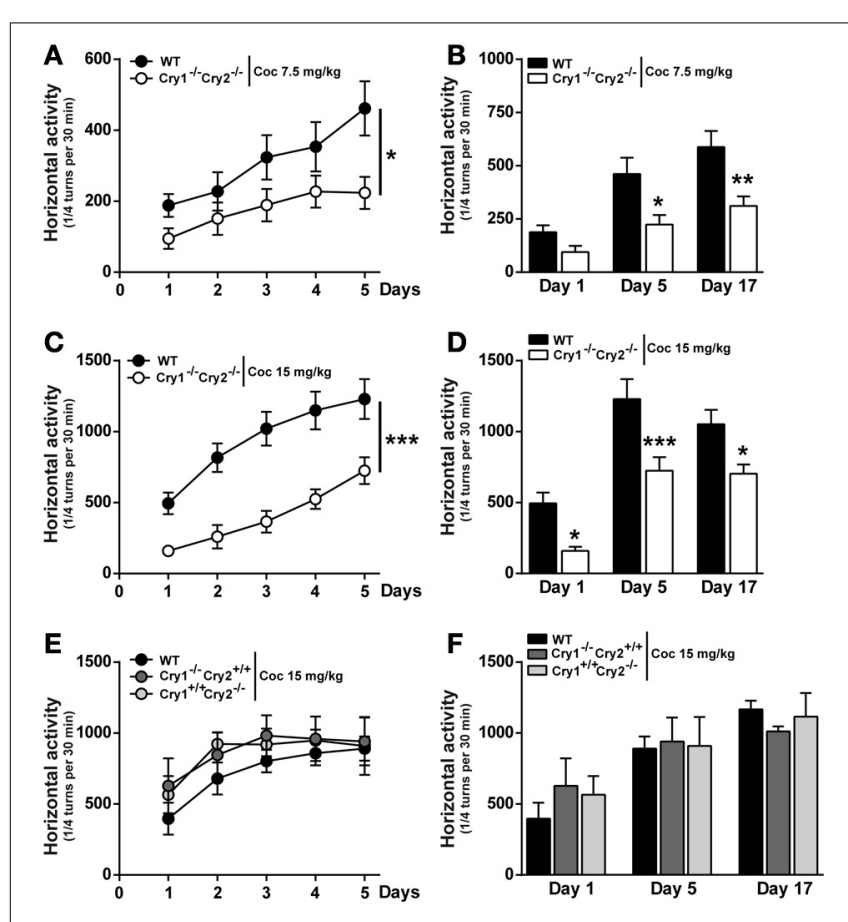

FIGURE 3 | Cocaine-induced acute hyperlocomotion and locomotor sensitization in Cry $\mathbf{1}^{-/-}$Cry2 ${ }^{-/-}$mice. (A and C) Locomotor activity induced by repeated cocaine administration $(7.5$ and $15 \mathrm{mg} / \mathrm{kg})$ in wild type (WT) and $\mathrm{Cry}^{-/-} \mathrm{Cry} 2^{-/-}$mice ( $n=10-12$ per experimental group). Data (means \pm sem) were analyzed using Two-Way ANOVA repeated measures: A [Time $\times$ Genotype: $F_{(4,76)}=2.783, P=0.0325$; Time: $F_{(4,76)}=17.95$, $P<0.0001$; Genotype: $F_{(1,19)}=3.883, P=0.0635$ ], C [Time $\times$ Genotype: $F_{(4,76)}=3.302, P=0.015$; Time: $F_{(4,76)}=53.45, P<0.0001$; Genotype: $F_{(1,19)}=17.98, P=0.0004$ ]. (B and $\left.\mathbf{D}\right)$ Cumulative locomotor activity of

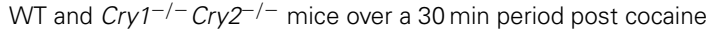
administration. Data (means \pm sem) were analyzed using Two-Way ANOVA repeated measures: (B) [Time $\times$ Genotype: $F_{(2,38)}=3.907, P=0.0288$; Time: $F_{(2,38)}=41.05, P<0.0001$; Genotype: $F_{(1,19)}=8.998$, $P=0.0074]$, (D) [Time $\times$ Genotype: $F_{(2,38)}=0.8807, P=0.4228$; Time: $F_{(2,38)}=48.61, P<0.0001$; Genotype: $\left.F_{(1,19)}=14.73, P=0.0012\right]$.

(E) Locomotor activity induced by repeated cocaine administration $(15 \mathrm{mg} / \mathrm{kg})$ in WT $(n=12), \mathrm{Cry}^{-/-} / \mathrm{Cry} 2^{+/+}(n=12)$ and Cry $1^{+/+} / \mathrm{Cry} 2^{-1-}$ $(n=5)$ mice. Data (means \pm sem) were analyzed using Two-Way ANOVA repeated measures: [Time $\times$ Genotype: $F_{(8,104)}=0.3432, P=0.9470$; Time: $F_{(4,104)}=9.940, P<0.0001$; Genotype: $F_{(2,26)}=0.4848$, $P=0.6213]$. (F) Cumulative locomotor activity of WT, Cry $1^{-/-} / \mathrm{Cry} 2^{+/+}$and Cry $1^{+/+} / \mathrm{Cry}^{-/-}$mice over a 30 min period post cocaine Data (means \pm sem) were analyzed using Two-Way ANOVA repeated measures: [Time $\times$ Genotype: $F_{(4,52)}=0.9167, P=0.4613$; Time: $F_{(2,52)}=16.52$,

$P<0.0001$; Genotype: $F_{(2,26)}=0.07071, P=0.9319$ ]. ${ }^{*} p<0.05$, ** $p<0.01,{ }^{* * *} p<0.001$.

rodents (Brami-Cherrier et al., 2005). As illustrated in Figure 3, single administration of cocaine (Dayl, 7.5 and $15 \mathrm{mg} / \mathrm{kg}$ ) induced higher locomotor responses in WT mice compared to $C r y 1^{-/-} C r y 2^{-/-}$mice (Figures 3A-D). When normalizing locomotor activity following cocaine injection to baseline activity, cocaine-induced hyperlocomotion remained significantly higher in WT mice compared to Cry $1^{-/-} C r y 2^{-/-}$mice (Supplemental Figure 1). Despite this reduced acute hyperlocomotion, Cry1 $1^{-/-} \mathrm{Cr} y 2^{-/-}$mice develop locomotor sensitization following repeated administration of cocaine (7.5 and $15 \mathrm{mg} / \mathrm{kg}$ ) (Figures 3A-D). On the other hand, Cry $1^{-/-} \mathrm{Cr} y 2^{+/+}$ and $\mathrm{Cry} \mathrm{I}^{+/+} \mathrm{Cr} y 2^{-/-}$mice displayed a normal acute and sensitized locomotor response to cocaine (Figures 3E,F). These results suggest that Cry genes are involved in the acute locomotor effect induced by cocaine but are not required for sensitization.

\section{COCAINE-INDUCED ERK ACTIVATION IN Cry1 ${ }^{-/-}$Cry2-/- MICE}

Acute administration of drugs of abuse, including cocaine, leads to a rapid and transient activation of ERK in the dorsal striatum and in the nucleus accumbens (NAcc) (Valjent et al., 2000, 2004; Gangarossa et al., 2013). As such, ERK can be used as a marker for neuronal activity. Moreover, ERK activation participates in some long-lasting behavioral changes induced by cocaine (Lu et al., 2006; Girault et al., 2007). To evaluate possible changes in striatal ERK activity, we examined the levels of ERK phosphorylation by immunofluorescence $10 \mathrm{~min}$ after a single cocaine administration $(7.5$ or $15 \mathrm{mg} / \mathrm{kg})$. Consistent with previous findings (Bertran-Gonzalez et al., 2008), cocaine (7.5 and $15 \mathrm{mg} / \mathrm{kg}$ ) elicited a significant increase in the number of P-ERK positive cells within the dorsal striatum and the NAcc core and shell of WT mice (Figures 4A,B). Although, basal ERK phosphorylation is strongly reduced in the dorsal striatum of $\mathrm{Cry} 1^{-/-} \mathrm{Cr} y 2^{-/-}$mice, this effect was significantly diminished within the dorsal striatum and the NAcc core and displayed a trend toward a decrease in the NAcc shell when $C r y 1^{-/-} C r y 2^{-/-}$mice were injected with $7.5 \mathrm{mg} / \mathrm{kg}$ of cocaine (Figures 4 A,B). The opposite profile was observed when cocaine at the dose of $15 \mathrm{mg} / \mathrm{kg}$ was administrated (Figures 4A,B). Importantly, the observed decrease in ERK phosphorylation is not a consequence of a low total level of ERK since western blot analysis of striatal total protein ERK did not reveal a significant difference in $C r y 1^{-/-} C r y 2^{-/-}$mice (Figure 4C). It is interesting to note that the slight decrease observed on basal ERK phosphorylation apparent by immunofluorescence was not detected by immunoblotting. This discrepancy may be attributable to the fact that immunoblotting detects an average of signaling events occurring in mixed populations of cells while immunofluorescence allows the identification of specific populations of cells in which a strong activation of ERK takes place. Overall, these data indicate that basal ERK phosphorylation is lower in medium-sized spiny neurons in Cry $1^{-/-} \mathrm{Cry} 2^{-/-}$ mice compared to WT mice but that the cocaine is nevertheless able to elicit ERK activation. These data correlate with the low baseline activity in $C r y 1^{-/-} C r y 2^{-/-}$mice but the preserved sensitization to cocaine, which depends on ERK phosphorylation in the striatum (Valjent et al., 2000).

\section{DISCUSSION}

In the present study, we characterized the behavioral consequences of full genetic disruption of the circadian clock, through deletion of both paralogs of the core circadian transcriptional repressor cryptochrome (Cry1 and Cry2). Our findings revealed that the lack of Cry1 and Cry2 genes (Cry $\left.1^{-/-} \mathrm{Cr} y 2^{-/-}\right)$elicits cognitive dysfunction, promotes anxiety-related behavior and results in a decreased sensitivity to cocaine but does not affect depression-like behavior. Interestingly, cognitive function and anxiety-related behaviors but none of the other behavioral parameters were also altered in mice lacking either Cryl or Cry2. 

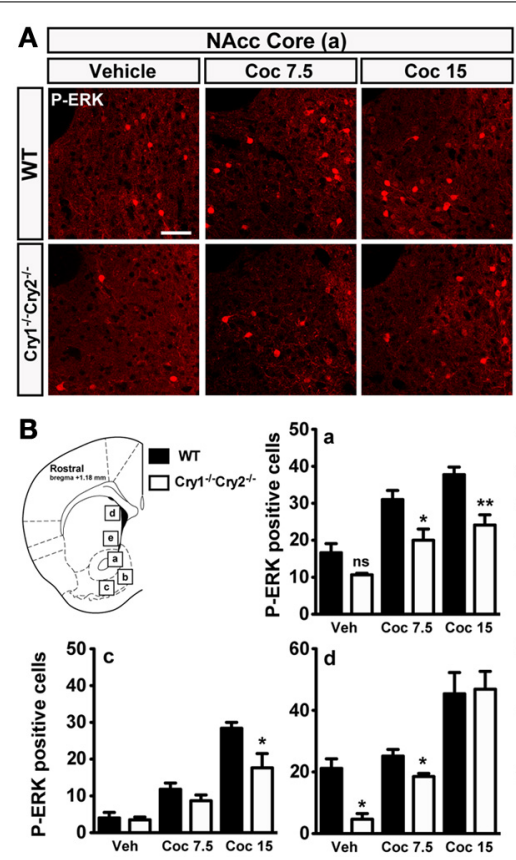

FIGURE 4 | Cocaine-induced ERK activation in $\mathrm{Cry1}^{-/-} \mathrm{Cry2}^{-/-}$mice.

(A) Immunofluorescence pictures showing P-ERK in the NAcc Core and Shell of wild type (WT) and $\mathrm{Cry} 1^{-1-} \mathrm{Cry} 2^{-/-}$mice treated with vehicle (veh) (WT, $n=3 ; C_{r y} 1^{-/-}$Cry2 $\left.{ }^{-1-}, n=3\right)$, cocaine $7.5 \mathrm{mg} / \mathrm{kg}$ (Coc7.5) (WT, $n=3 ;$ Cry $^{-/-}$Cry2 ${ }^{-/-}, n=3$ ) and cocaine $15 \mathrm{mg} / \mathrm{kg}$ (Coc15) (WT, $\left.n=4 ; \mathrm{Cry}^{-/-} \mathrm{Cry}^{-/-}, n=4\right)$. (B) Quantification of P-ERK positive

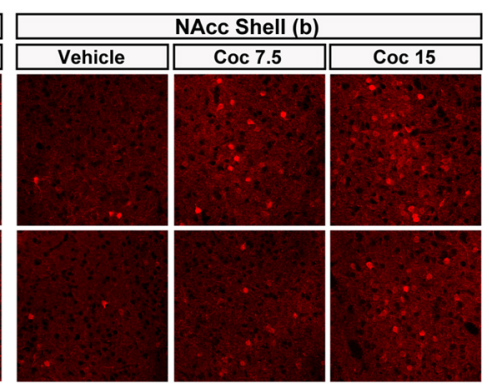

C
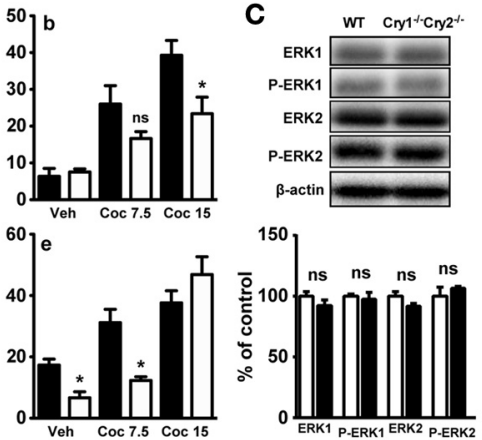

neurons in NAcc core (a), NAcc medial shell (b), NAcc ventral shell (c), dorso-medial striatum (d), and ventro-medial striatum (e). Data (means \pm sem) were analyzed using an unpaired Student's $t$-test: ${ }^{*} p<0.05$, ${ }^{* *} p<0.01$. (C) Quantification of ERK1 and ERK2 expression levels in wild type (WT) $(n=6)$ and Cry ${ }^{-/-C r y 2^{-/}}$mice $(n=6)$ (means \pm sem).
We found that $C r y 1^{-/-} / C r y 2^{-/-}$mice maintain a daily pattern of activity when kept in a normal light-dark cycle but are hypoactive during the dark phase. Moreover, Cry $1^{-/-} / \mathrm{Cr} y 2^{-/-}$ mice showed a rapid decline in activity following exposure to a novel environment compared to WT mice, supporting the notion that circadian clock proteins may control adaptation to novelty (Kondratova et al., 2010). No difference in locomotor activity was observed between WT mice and single knockout mice for Cry1 or Cry2. Interestingly, all cryptochrome mutants showed lower overall performance compared to WT in the rotarod task, but motor performance improved in all strains, indicating that Cry1 and Cry2 genes are not required for motor learning (Supplemental Figure 2). Low initial rotarod performance in cryptochrome mutants may reflect elevated anxiety in this task. Similar to our observations in single cryptochrome mutants, no overt differences in spontaneous locomotor activity were previously described in single knockout mice for the circadian transcriptional repressors mPer1 or mPer2 (Abarca et al., 2002; Spencer et al., 2013). In contrast, knockout mice for the circadian transcriptional activators Clock, Bmal1 and NPAS2 are hyperactive (Dudley et al., 2003; McClung, 2006; Kondratova et al., 2010). These results support the notion that different circadian clock genes can mediate opposing effects on locomotor behavior, corresponding to their role as transcriptional activators or repressors.
The circadian system has been proposed to play a critical role in memory formation (Gerstner and Yin, 2010; Kondratova et al., 2010). Several pathways implicated in memory formation show circadian oscillation (Eckel-Mahan and Storm, 2009). However, the precise involvement of circadian clock genes and their role as core pacemakers on memory formation is less clear. Mice lacking NPAS2 show impaired cued and contextual fear learning (Garcia et al., 2000). Similarly, BMAL1 knockout mice show impaired contextual habituation (Kondratova et al., 2010). In contrast to these mutants for circadian transcriptional activators, mice lacking $m$ Per 1 and mPer 2 show normal spatial learning and contextual fear learning (Zueger et al., 2006; Feillet et al., 2008). Similarly, knockout mice for both Cry1 and Cry2 display normal spatial learning (Van der Zee et al., 2008) and intact cued (present study) and contextual fear learning (Van der Zee et al., 2008). Interestingly, Cry $1^{-/-} / C r y 2^{-/-}$mice have intact shortterm interval timing (Papachristos et al., 2011) but are unable to learn place-time-of-day associations (Van der Zee et al., 2008). Our study clearly shows learning deficits in the object recognition task in Cry double knockout mice as well as Cry1 and Cry2 single knockout mice. Memory impairments in Cry mutants are unlikely to result from low attention given that Cry 1 and Cry 2 mutant mice showed normal object exploration. One potential explanation for the specificity of these cognitive deficits is that Cry mutants may display learning deficits when cognitive demands are higher 
(place vs. place-time-of-day associations) or when the incentive for learning is lower (spontaneous exploration vs. food reward or shock punishment). Moreover, these data indicate that different circadian clock genes disruption affects specific types of learning.

Aberrant light-dark rhythms directly induce depression-like behavior in rodents (Gonzalez and Aston-Jones, 2008; Fonken et al., 2009; Monje et al., 2011). This has led to the hypothesis that alterations in light may indirectly alter mood through changes in the circadian clock. However, a recent study demonstrated that mice exposed to a $3.5 \mathrm{~h}$-light $/ 3.5 \mathrm{~h}$-dark cycle developed depression-like behavior while maintaining a normal amount of sleep and without showing significant disruption of circadian clock components (LeGates et al., 2012). Conversely, we here show that full disruption of the circadian clock through deletion of the paralog pair of cryptochromes did not cause depression-related behaviors in mice maintained in a standard $12 \mathrm{~h}$-light/12 h-dark cycle. This further suggests that altered mood in other circadian clock gene mutants may be a consequence of the role of clock gene products as transcription factors and altered expression of their tissue-specific target genes. Clock mutant mice display reduced depression-like behaviors (Easton et al., 2003; Roybal et al., 2007). Interestingly, Per $2^{B r d m 1}$ mutant mice that show lower activity and expression of MAO-A and display a depression-resistant-like phenotype (Hampp et al., 2008). These effects may depend on paralogspecific gene interactions. For instance, the E-box element of the MAO-A promoter was shown to serve as a binding site for the NPAS2/BMAL1 heterodimer but not for the CLOCK/BMAL1 heterodimer (Hampp et al., 2008). In the same study, mPer2 strongly increased, whereas Cryl only marginally decreased transcriptional regulation of MAO-A (Hampp et al., 2008). We found no significant effect of Cry1 and/or Cry2 gene inactivation on MAO-A expression (data not shown) or depressionlike behavior in the forced swim test. Moreover, Afterhours mutant mice, carrying an FBXL3 mutation resulting in decreased ubiquitination and degradation of CRY (Busino et al., 2007; Godinho et al., 2007; Siepka et al., 2007), showed no spontaneous depression-like behavior in the forced swim test (Keers et al., 2012). These findings further indicate that cryptochromes may not have a critical influence on depression-related behavior and raises the question of causality for described associations between Cry1 and Cry2 single nucleotide polymorphisms with mood disorders in humans (Lavebratt et al., 2010; Soria et al., 2010).

Few studies have investigated the effect of circadian clock genes on anxiety. Whereas clock mutant mice appear to be less anxious (Easton et al., 2003; Roybal et al., 2007), mice lacking both mPer 1 and mPer 2 showed elevated anxiety in a range of behavioral tests, whereas no phenotypes were observed in single deficient mice (Spencer et al., 2013). Cry1 or Cry2 single knockout mice showed elevated anxiety in the elevated plus maze, but less prominent compared to mice lacking both Cryl and Cry2 that displayed robust anxiety-related behaviors across tests. This is in line with the observation that Afterhours mutant mice showed lower anxiety-related behaviors (Keers et al., 2012) and suggests largely complementary roles of Cry1 and Cry 2 with an opposite influence of the circadian transcriptional activators and repressors on anxiety-related behavior. Lesions of the suprachiasmatic nucleus elicit antidepressant-like effects but do not affect anxiety-related behaviors (Engelmann et al., 1998; Tataroglu et al., 2004; Tuma et al., 2005). This suggests that elevated anxiety in $\mathrm{mPer} 1^{-/-} \mathrm{mPer} 2^{-/-}$mice and in $\mathrm{Cr} y 1^{-/-} \mathrm{Cr} y 2^{-/-}$mice may result from lack of function of these circadian clock genes in brain regions outside of the suprachiasmatic nucleus, such as the nucleus accumbens (Spencer et al., 2013).

Finally, circadian clock genes have been implicated in susceptibility to substance abuse disorders. Thus, Clock $\Delta 19$ mutant mice are more sensitive to the psychostimulant and rewarding effects of cocaine (McClung et al., 2005; Roybal et al., 2007) and self-administer more cocaine than WT mice (Ozburn et al., 2012). Although, $m P e r 1^{-/-}$mice are hyper responsive to the acute effects of cocaine and show a sensitized response following a single administration (Abarca et al., 2002), cocaine-induced self-administration and reinstatement do not differ from WT mice (Halbout et al., 2011). Interestingly, mPer2 $2^{-/-}$mice show a radically different phenotype (Abarca et al., 2002). While the acute response is decreased, $m P e r 2^{-/-}$mice display an exacerbated sensitization to the locomotor effects of cocaine (Abarca et al., 2002). Our study reveals that Cry1 and Cry2 single knockout mice show normal acute and sensitized responses to cocaine. Cry $1^{-/-} \mathrm{Cr} y 2^{-/-}$double knockout mice display reduced acute cocaine-induced hyperlocomotion, but they still develop locomotor sensitization to repeated administrations of cocaine. Similarly, baseline ERK phosphorylation was overall lower in Cry $1^{-/-} \mathrm{Cry2}^{-/-}$double knockout mice, but ERK phosphorylation increased following cocaine administration in the dorsal striatum and the NAcc, possibly accounting for the development of locomotor sensitization (Corvol et al., 2007). Altogether, our data suggest that in contrast to the other circadian clock genes, cryptochromes may not have a critical influence on cocainerelated behavior.

In conclusion, this study shows that disruption of the circadian clock, through deletion of one and/or both paralogs of the circadian core gene cryptochrome elicits cognitive dysfunction and promotes anxiety-related behaviors. In contrast, depression-related behaviors seem to be unaffected in cryptochrome mutant lines, and cocaine-related behaviors were only affected in mice lacking both cryptochrome paralogs during the acute phase of drug administration. Future studies will be necessary to decipher the mechanisms underlying the observed associations.

\section{ACKNOWLEDGMENTS}

This work was supported by Inserm and grants from ATIP-Avenir (Inserm), Sanofi-Aventis R\&D, from the Agence Nationale de la Recherche (ANR-2010-JCJC-1412) to Emmanuel Valjent and (ANR-2011-JCJC-052) to Xavier Bonnefont. Dimitri De Bundel was a recipient of a postdoctoral fellowship from the Fondation pour la Recherche Médicale (FRM). Anne Biever was a recipient of doctoral fellowship from the Fond National de la Recherche Luxembourg (FNR). We thank Freddy Jeanneteau for thoughtful discussion of the manuscript. Bert van der Horst (Erasmus MC, Rotterdam) is acknowledged for providing the original Cry mouse lines. 


\section{SUPPLEMENTARY MATERIAL}

The Supplementary Material for this article can be found online at: http://www.frontiersin.org/journal/10.3389/fnbeh.2013.00152/ abstract

Figure S1 | Cocaine-induced acute hyperlocomotion. Locomotor activity induced by acute cocaine administration $(7.5$ and $15 \mathrm{mg} / \mathrm{kg}$ ) in wild type (WT) and Cry1-/-Cry2 ${ }^{-/-}$mice ( $n=10-12$ per experimental group). Measurements are shown as (A) raw data and

(B) normalized data on the last day of habituation. Data (means \pm sem) were analyzed using an unpaired Student's $t$-test: ${ }^{*} p<0.05$, $* * p<0.01$.

\section{REFERENCES}

Abarca, C., Albrecht, U., and Spanagel, R. (2002). Cocaine sensitization and reward are under the influence of circadian genes and rhythm. Proc. Natl. Acad. Sci. U.S.A. 99, 9026-9030. doi: 10.1073/pnas. 142039099

Bertran-Gonzalez, J., Bosch, C., Maroteaux, M., Matamales, M., Herve, D., Valjent, E., et al. (2008). Opposing patterns of signaling activation in dopamine D1 and D2 receptor-expressing striatal neurons in response to cocaine and haloperidol. J. Neurosci. 28, 5671-5685. doi: 10.1523/JNEUROSCI.1039-08.2008

Brami-Cherrier, K., Valjent, E., Herve, D., Darragh, J., Corvol, J. C., Pages, C., et al. (2005). Parsing molecular and behavioral effects of cocaine in mitogen- and stress-activated protein kinase-1-deficient mice. J. Neurosci. 25, 11444-11454. doi: 10.1523/JNEUROSCI.1711-05.2005

Busino, L., Bassermann, F., Maiolica, A., Lee, C., Nolan, P. M., Godinho, S. I., et al. (2007). SCFFbxl3 controls the oscillation of the circadian clock by directing the degradation of cryptochrome proteins. Science 316, 900-904. doi: 10.1126/science. 1141194

Corvol, J. C., Valjent, E., Pascoli, V., Robin, A., Stipanovich, A., Luedtke, R. R., et al. (2007). Quantitative changes in Galphaolf protein levels, but not D1 receptor, alter specifically acute responses to psychostimulants. Neuropsychopharmacology 32, 1109-1121. doi: 10.1038/sj.npp.1301230

De Bundel, D., Femenia, T., Dupont, C. M., Konradsson-Geuken, A., Feltmann, K., Schilstrom, B., et al. (2013). Hippocampal and prefrontal dopamine D1/5 receptor involvement in the memoryenhancing effect of reboxetine. Int. J. Neuropsychopharmacol. 16, 2041-2051. doi: 10.1017/ S1461145713000370

DeBruyne, J. P., Weaver, D. R., and Reppert, S. M. (2007). CLOCK and
NPAS2 have overlapping roles in the suprachiasmatic circadian clock. Nat. Neurosci. 10, 543-545. doi: $10.1038 / \mathrm{nn} 1884$

Disner, S. G., Beevers, C. G., Haigh, E. A., and Beck, A. T. (2011). Neural mechanisms of the cognitive model of depression. Nat. Rev. Neurosci. 12, 467-477. doi: 10.1038/nrn3027

Dong, L., Bilbao, A., Laucht, M., Henriksson, R., Yakovleva, T., Ridinger, M., et al. (2011). Effects of the circadian rhythm gene period 1 (per1) on psychosocial stressinduced alcohol drinking. Am. J. Psychiatry 168, 1090-1098. doi: 10.1176/appi.ajp.2011.10111579

Dudley, C. A., Erbel-Sieler, C., Estill, S. J., Reick, M., Franken, P., Pitts, S., et al. (2003). Altered patterns of sleep and behavioral adaptability in NPAS2-deficient mice. Science 301, 379-383. doi: 10.1126/science. 1082795

Easton, A., Arbuzova, J., and Turek, F. W. (2003). The circadian Clock mutation increases exploratory activity and escape-seeking behavior. Genes Brain Behav. 2, 11-19. doi: $\quad 10.1034 / j .1601-183 X .2003$. 00002.x

Eckel-Mahan, K. L., and Storm, D. R. (2009). Circadian rhythms and memory: not so simple as cogs and gears. EMBO Rep. 10, 584-591. doi: 10.1038/embor.2009.123

Engelmann, M., Ebner, K., Landgraf, R., and Wotjak, C. T. (1998). Swim stress triggers the release of vasopressin within the suprachiasmatic nucleus of male rats. Brain Res. 792, 343-347. doi: 10.1016/S0006-8993 (98)00243-1

Falcon, E., and McClung, C. A. (2009). A role for the circadian genes in drug addiction. Neuropharmacology 56(Suppl. 1), 91-96. doi: 10.1016/j. neuropharm.2008.06.054

Feillet, C. A., Mendoza, J., Albrecht, U., Pevet, P., and Challet, E. (2008). Forebrain oscillators ticking with different clock hands. Mol. Cell. Neurosci. 37, 209-221. doi: 10.1016/ j.mcn.2007.09.010

Figure S2 | Motor coordination and learning in $\mathrm{Cry1}^{-/-} \mathrm{Cry2}^{-/-}$mice.

(A) Curve showing coordination and motor learning in WT $(n=16)$,

Cry $^{-/-} \mathrm{Cry}^{+/+}(n=5), \mathrm{Cry}^{+/+} \mathrm{Cry}^{-/-}(n=6)$ and Cry $1^{-/-} \mathrm{Cry}^{-/-}$

$(n=8)$ mice over a training period of 3 days. Data (means \pm sem) were analyzed using Two-Way ANOVA repeated measures [Time $\times$ Genotype: $F_{(6,62)}=0.1692, P=0.7813$; Time: $F_{(2,62)}=57.44, P<0.0001$;

Genotype: $F_{(3,31)}=22.40, P<0.0001$ ]. $\left(^{* * *} p<0.001\right.$ mutant mice vs. WT mice). (B) Percentage of learning in WT $(n=16), C r y 1^{-/-}$Cry $2^{+/+}$ $(n=5), C r y 1^{+/+}$Cry2 ${ }^{-1-}(n=6)$ and Cry $1^{-/-}$Cry2 $^{-/-}(n=8)$ Data (means \pm sem) were analyzed using Two-Way ANOVA repeated measures [Time $x$ Genotype: $F_{(3,31)}=2.034, P=0.1294$; Time: $F_{(1,31)}=113.8, P<0.0001$; Genotype: $\left.F_{(3,31)}=0.9203, P=0.4425\right]$. ${ }^{* * *} p<0.001$ Day 1 vs. Day 3$)$.

Fonken, L. K., Finy, M. S., Walton, J. C., Weil, Z. M., Workman, J. L., Ross, J., et al. (2009). Influence of light at night on murine anxietyand depressive-like responses. Behav. Brain Res. 205, 349-354. doi: 10.1016/j.bbr.2009.07.001

Gangarossa, G., Espallergues, J., de Kerchove d'Exaerde, A., El Mestikawy, S., Gerfen, C. R., Herve, D., et al. (2013). Distribution and compartmental organization of GABAergic medium-sized spiny neurons in the mouse nucleus accumbens. Front. Neural Circuits 7:22. doi: $10.3389 /$ fncir.2013.00022

Garcia, J. A., Zhang, D., Estill, S. J., Michnoff, C., Rutter, J., Reick, M., et al. (2000). Impaired cued and contextual memory in NPAS2-deficient mice. Science 288, 2226-2230. doi: 10.1126/ science.288.5474.2226

Gerstner, J. R., and Yin, J. C. (2010). Circadian rhythms and memory formation. Nat. Rev. Neurosci. 11, 577-588. doi: 10.1038/nrn2881

Girault, J. A., Valjent, E., Caboche, J., and Herve, D. (2007). ERK2: a logical AND gate critical for drug-induced plasticity? Curr. Opin. Pharmacol. 7, 77-85. doi: 10.1016/j. coph.2006.08.012

Godinho, S. I., Maywood, E. S., Shaw, L., Tucci, V., Barnard, A. R., Busino, L., et al. (2007). The after-hours mutant reveals a role for Fbxl3 in determining mammalian circadian period. Science 316, 897-900. doi: $10.1126 /$ science. 1141138

Gomez-Galan, M., De Bundel, D., Van Eeckhaut, A., Smolders, I., and Lindskog, M. (2013). Dysfunctional astrocytic regulation of glutamate transmission in a rat model of depression. Mol. Psychiatry 18, 582-594. doi: 10.1038/mp.2012.10

Gonzalez, M. M., and Aston-Jones, G. (2008). Light deprivation damages monoamine neurons and produces a depressive behavioral phenotype in rats. Proc. Natl. Acad. Sci. U.S.A. 105, 4898-4903. doi: 10.1073/pnas. 0703615105
Halbout, B., Perreau-Lenz, S., Dixon, C. I., Stephens, D. N., and Spanagel, R. (2011). Per1(Brdm1) mice selfadminister cocaine and reinstate cocaine-seeking behaviour following extinction. Behav. Pharmacol. 22, 76-80. doi: 10.1097/FBP.0b013 e328341e9ca

Hampp, G., and Albrecht, U. (2008). The circadian clock and mood-related behavior. Commun. Integr. Biol. 1, 1-3. doi: 10.4161/cib.1.1.6286

Hampp, G., Ripperger, J. A., Houben, T., Schmutz, I., Blex, C., PerreauLenz, S., et al. (2008). Regulation of monoamine oxidase A by circadian-clock components implies clock influence on mood. Curr. Biol. 18, 678-683. doi: 10.1016/j.cub.2008.04.012

Keers, R., Pedroso, I., Breen, G., Aitchison, K. J., Nolan, P. M., Cichon, S., et al. (2012). Reduced anxiety and depression-like behaviours in the circadian period mutant mouse afterhours. PLoS ONE 7:e38263. doi: 10.1371/ journal.pone. 0038263

Kissling, C., Retz, W., Wiemann, S., Coogan, A. N., Clement, R. M., Hunnerkopf, R., et al. (2008). A polymorphism at the 3 '-untranslated region of the CLOCK gene is associated with adult attention-deficit hyperactivity disorder. Am. J. Med. Genet. B Neuropsychiatr. Genet. 147, 333-338. doi: 10.1002/ajmg.b.30602

Kondratova, A. A., Dubrovsky, Y. V., Antoch, M. P., and Kondratov, R. V. (2010). Circadian clock proteins control adaptation to novel environment and memory formation. Aging 2, 285-297.

Kovanen, L., Saarikoski, S. T., Haukka, J., Pirkola, S., Aromaa, A., Lonnqvist, J., et al. (2010). Circadian clock gene polymorphisms in alcohol use disorders and alcohol consumption. Alcohol Alcohol. 45, 303-311. doi: 10.1093/alcalc/agq035

Lavebratt, C., Sjoholm, L. K., Soronen, P., Paunio, T., Vawter, M. P., Bunney, 
W. E., et al. (2010). CRY2 is associated with depression. PLoS ONE 5:e9407. doi: 10.1371/journal.pone. 0009407

LeGates, T. A., Altimus, C. M., Wang, H., Lee, H. K., Yang, S., Zhao, H., et al. (2012). Aberrant light directly impairs mood and learning through melanopsin-expressing neurons. Nature 491, 594-598. doi: 10.1038 /nature 11673

Lu, L., Koya, E., Zhai, H., Hope, B. T., and Shaham, Y. (2006). Role of ERK in cocaine addiction. Trends Neurosci. 29, 695-703. doi: 10.1016/ j.tins.2006.10.005

McClung, C. A., Sidiropoulou, K., Vitaterna, M., Takahashi, J. S., White, F. J., Cooper, D. C., et al. (2005). Regulation of dopaminergic transmission and cocaine reward by the Clock gene. Proc. Natl. Acad. Sci. U.S.A. 102, 9377-9381. doi: 10.1073/pnas.0503584102

McClung, C. R. (2006). Twocomponent signaling provides the major output from the cyanobacterial circadian clock. Proc. Natl. Acad. Sci. U.S.A. 103, 11819-11820. doi: 10.1073/pnas.0605295103

Millan, M. J., Agid, Y., Brune, M., Bullmore, E. T., Carter, C. S., Clayton, N. S., et al. (2012). Cognitive dysfunction in psychiatric disorders: characteristics, causes and the quest for improved therapy. Nat. Rev. Drug Discov. 11, 141-168. doi: 10.1038/nrd3628

Mohawk, J. A., Green, C. B., and Takahashi, J. S. (2012). Central and peripheral circadian clocks in mammals. Annu. Rev. Neurosci. 35: 445-462. doi: 10.1146/annurevneuro-060909-153128

Monje, F. J., Cabatic, M., Divisch, I., Kim, E. J., Herkner, K. R., Binder, B. R., et al. (2011). Constant darkness induces IL-6dependent depression-like behavior through the NF-kappaB signaling pathway. J. Neurosci. 31, 9075-9083. doi: 10.1523/ JNEUROSCI.1537-11.2011

Nicholas, B., Rudrasingham, V., Nash, S., Kirov, G., Owen, M. J., and Wimpory, D. C. (2007). Association of Per1 and Npas2 with autistic disorder: support for the clock genes/social timing hypothesis. Mol. Psychiatry 12, 581-592. doi: 10.1038/sj.mp.4001953

Nievergelt, C. M., Kripke, D. F., Barrett, T. B., Burg, E., Remick, R. A., Sadovnick, A. D., et al. (2006). Suggestive evidence for association of the circadian genes PERIOD3 and ARNTL with bipolar disorder. Am. J. Med. Genet. B Neuropsychiatr. Genet. 141B, 234-241. doi: 10.1002/ ajmg.b.30252
Ozburn, A. R., Larson, E. B., Self, D. W., and McClung, C. A. (2012). Cocaine self-administration behaviors in ClockDelta19 mice. Psychopharmacology (Berl.) 223, 169-177. doi: 10.1007/s00213-0122704-2

Papachristos, E. B., Jacobs, E. H., and Elgersma, Y. (2011). Interval timing is intact in arrhythmic Cry1/Cry2-deficient mice. J. Biol. Rhythms 26, 305-313. doi: 10.1177/ 0748730411410026

Partonen, T., Treutlein, J., Alpman, A., Frank, J., Johansson, C., Depner, M., et al. (2007). Three circadian clock genes Per2, Arntl, and Npas2 contribute to winter depression. Ann. Med. 39, 229-238. doi: 10.1080/ 07853890701278795

Porsolt, R. D., Le Pichon, M., and Jalfre, M. (1977). Depression: a new animal model sensitive to antidepressant treatments. Nature 266, 730-732. doi: 10.1038/266730a0

Roybal, K., Theobold, D., Graham, A., DiNieri, J. A., Russo, S. J., Krishnan, V., et al. (2007). Manialike behavior induced by disruption of CLOCK. Proc. Natl. Acad. Sci. U.S.A. 104, 6406-6411. doi: 10.1073/pnas.0609625104

Shi, J., Wittke-Thompson, J. K., Badner, J. A., Hattori, E., Potash, J. B., Willour, V. L., et al. (2008). Clock genes may influence bipolar disorder susceptibility and dysfunctional circadian rhythm. Am. J. Med. Genet. B Neuropsychiatr. Genet. 147B, 1047-1055. doi: 10.1002/ajmg.b.30714

Shi, S., Hida, A., McGuinness, O. P., Wasserman, D. H., Yamazaki, S., and Johnson, C. H. (2010). Circadian clock gene Bmall is not essential; functional replacement with its paralog, Bmal2. Curr. Biol. 20, 316-321. doi: 10.1016/j.cub. 2009.12.034

Siepka, S. M., Yoo, S. H., Park, J., Song, W., Kumar, V., Hu, Y., et al. (2007). Circadian mutant overtime reveals F-box protein FBXL3 regulation of cryptochrome and period gene expression. Cell 129, 1011-1023. doi: 10.1016/j.cell.2007.04.030

Sipila, T., Kananen, L., Greco, D., Donner, J., Silander, K., Terwilliger, J. D., et al. (2010). An association analysis of circadian genes in anxiety disorders. Biol. Psychiatry 67, 1163-1170. doi: 10.1016/j.biopsych. 2009.12.011

Soria, V., Martinez-Amoros, E., Escaramis, G., Valero, J., PerezEgea, R., Garcia, C., et al. (2010). Differential association of circadian genes with mood disorders: CRY1 and NPAS2 are associated with unipolar major depression and
CLOCK and VIP with bipolar disorder. Neuropsychopharmacology 35, 1279-1289. doi: 10.1038/npp 2009.230

Spencer, S., Falcon, E., Kumar, J., Krishnan, V., Mukherjee, S., Birnbaum, S. G., et al. (2013). Circadian genes Period 1 and Period 2 in the nucleus accumbens regulate anxiety-related behavior. Eur. J. Neurosci. 37, 242-250. doi: 10.1111/ ejn. 12010

Takahashi, J. S., Hong, H. K., Ko, C. H., and McDearmon, E. L. (2008) The genetics of mammalian circadian order and disorder: implications for physiology and disease. Nat. Rev. Genet. 9, 764-775. doi: 10.1038/nrg2430

Tataroglu, O., Aksoy, A., Yilmaz, A., and Canbeyli, R. (2004). Effect of lesioning the suprachiasmatic nuclei on behavioral despair in rats. Brain Res. 1001, 118-124. doi: 10.1016/j. brainres.2003.11.063

Tuma, J., Strubbe, J. H., Mocaer, E., and Koolhaas, J. M. (2005). Anxiolyticlike action of the antidepressant agomelatine (S 20098) after a social defeat requires the integrity of the SCN. Eur. Neuropsychopharmacol. 15, 545-555. doi: 10.1016/j. euroneuro.2005.02.004

Valjent, E., Corvol, J. C., Pages, C., Besson, M. J., Maldonado, R., and Caboche, J. (2000). Involvement of the extracellular signal-regulated kinase cascade for cocaine-rewarding properties. J. Neurosci. 20, 8701-8709.

Valjent, E., Pagès, C., Hervé, D., Girault, J. A., and Caboche, J. (2004). Addictive and non-addictive drug induce distinct and specific patterns of ERK activation in mouse brain. Eur. J. Neurosci. 19, 1826-1836. doi: 10.1111/j.1460-9568.2004.03278.x

van der Horst, G. T., Muijtjens, M., Kobayashi, K., Takano, R. Kanno, S., Takao, M., et al. (1999). Mammalian Cry1 and Cry2 are essential for maintenance of circadian rhythms. Nature 398, 627-630. doi: 10.1038/19323

Van der Zee, E. A., Havekes, R., Barf, R. P., Hut, R. A., Nijholt, I. M., Jacobs, E. H., et al. (2008). Circadian timeplace learning in mice depends on Cry genes. Curr. Biol. 18, 844-848. doi: 10.1016/j.cub.2008.04.077

Vitaterna, M. H., Selby, C. P., Todo, T., Niwa, H., Thompson, C., Fruechte, E. M., et al. (1999). Differential regulation of mammalian period genes and circadian rhythmicity by cryptochromes 1 and 2. Proc. Natl. Acad. Sci. U.S.A. 96, 12114-12119. doi: 10.1073/pnas.96.21.12114

Wang, X., Mozhui, K., Li, Z., Mulligan, M. K., Ingels, J. F., Zhou, X., et al.
(2012). A promoter polymorphism in the Per3 gene is associated with alcohol and stress response. Transl. Psychiatry 2:e73. doi: 10.1038/tp. 2011.71

Wulff, K., Gatti, S., Wettstein, J. G., and Foster, R. G. (2010). Sleep and circadian rhythm disruption in psychiatric and neurodegenerative disease. Nat. Rev. Neurosci. 11, 589-599. doi: 10.1038/nrn2868

Xu, X., Breen, G., Chen, C. K., Huang, Y. S., Wu, Y. Y., and Asherson, P. (2010). Association study between a polymorphism at the 3 'untranslated region of CLOCK gene and attention deficit hyperactivity disorder. Behav. Brain Funct. 6:48. doi: 10.1186/1744-9081-6-48

Zheng, B., Albrecht, U., Kaasik, K., Sage, M., Lu, W., Vaishnav, S., et al. (2001). Nonredundant roles of the mPer1 and mPer2 genes in the mammalian circadian clock. Cell 105, 683-694. doi: 10.1016/S00928674(01)00380-4

Zueger, M., Urani, A., Chourbaji, S., Zacher, C., Lipp, H. P., Albrecht, U., et al. (2006). mPerl and mPer2 mutant mice show regular spatial and contextual learning in standardized tests for hippocampus-dependent learning. J. Neural Transm. 113, 347-356. doi: 10.1007/s00702-005-0322-4

Conflict of Interest Statement: The authors declare that the research was conducted in the absence of any commercial or financial relationships that could be construed as a potential conflict of interest.

Received: 06 September 2013; accepted: 04 October 2013; published online: 24 October 2013.

Citation: De Bundel D, Gangarossa $G$, Biever A, Bonnefont $X$ and Valjent $E$ (2013) Cognitive dysfunction, elevated anxiety, and reduced cocaine response in circadian clock-deficient cryptochrome knockout mice. Front. Behav. Neurosci. 7:152. doi: 10.3389/ fnbeh.2013.00152

This article was submitted to the journal Frontiers in Behavioral Neuroscience. Copyright (C) 2013 De Bundel, Gangarossa, Biever, Bonnefont and Valjent. This is an open-access article distributed under the terms of the Creative Commons Attribution License (CC BY). The use, distribution or reproduction in other forums is permitted, provided the original author(s) or licensor are credited and that the original publication in this journal is cited, in accordance with accepted academic practice. No use, distribution or reproduction is permitted which does not comply with these terms. 